\title{
Major complication after Histoacryl injection for endoscopic treatment of bleeding peptic ulcer
}

A 49-year-old man in hemorrhagic shock because of melena and hematemesis was referred from another hospital. On admission he was still normotensive (red cell count $2.08 \times 106 / \mu \mathrm{L}$, hemoglobin $61 \mathrm{~g} / \mathrm{L}$ ). He had no prior known medical condition and did not take any medication regularly. Emergency endoscopy revealed a large amount of fresh coagulated blood and bleeding from the arterial vessels in the stomach cardia. Endoscopic sclerotherapy was carried out with Sclerovein (Chemische Fabrik Kreussler \& Co. GmbH, Wiesbaden, Germany) and N-butyl-2-cyanoacrylate (Histoacryl; B. Braun, Melsungen, Germany). After injection of $1.5 \mathrm{~mL}$ Histoacryl, the bleeding stopped. On day 2 , the patient had fever and complained of unbearable pain in the upper abdomen. A plain abdominal radiograph showed multiple linear radiopaque densities in all branches of celiac trunk ( Fig. 1). Abdominal computed tomography (CT) revealed a perforated gallbladder with development of gangrene, as well as multiple infarctions in spleen, left liver lobe, and the hypoperfused distal part of pancreas ( Fig.2). On day 7, laparotomy was carried out, and the gallbladder and spleen were removed and abdominal drains were placed. The patient stayed in the intensive care unit for several days, with total parenteral nutrition and intravenous antibiotic therapy. He then developed acute pancreatitis with an external pancreatic fistula, which was treated conservatively. He was discharged on day 36 after the surgery.

Serious complications of endoscopic injection therapy may be avoided by using of adhesive agents to treat bleeding gastric ulcers [1]. However, as the present case and a few similar cases show [1 - 3], inadvertent injection of any sclerosant can result in thrombosis of the splenic artery. Endoscopists should be aware of the close anatomic relationship between the stomach wall and the splenic artery. Inadvertent injection of Histoacryl into the splenic artery, in comparison with other agents, tends to obliterate several vessels of the celiac axis [3]. As suggested previously, Histoacryl injection should be considered as a last resort in the endo-

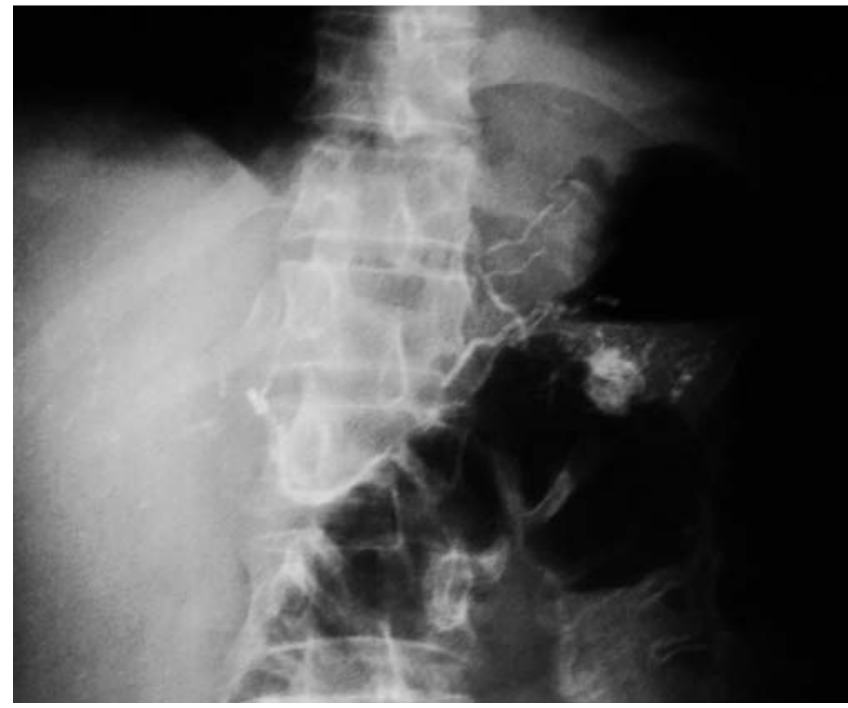

Fig. 1 Plain abdominal radiogram after Histoacryl injection in a 49-year-old man in hemorrhagic shock because of melena and hematemesis. Radiopaque densities in the branches of the celiac trunk can be seen.

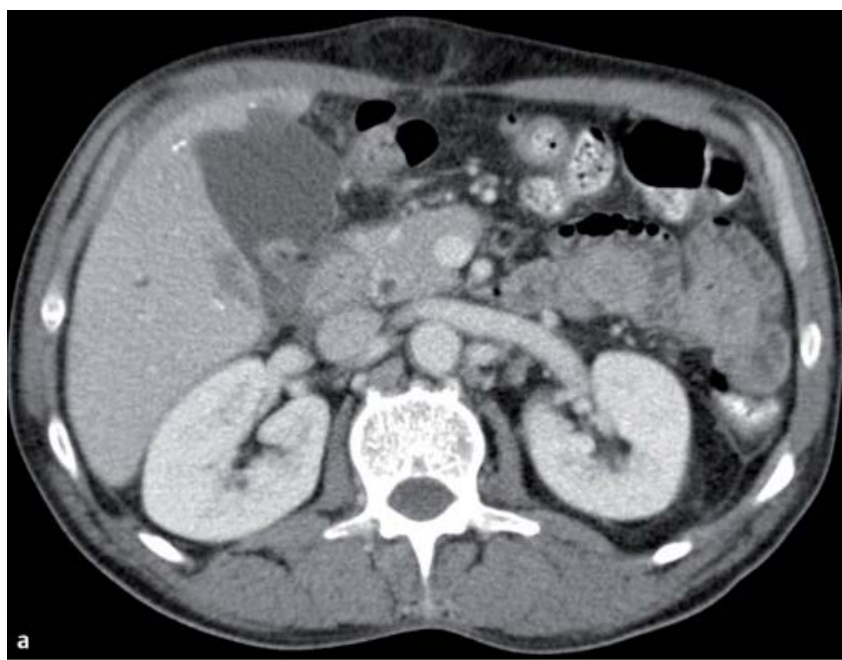

Fig. 2 Abdominal computed tomography (CT) scan showing a gallbladder necrosis with perforation and b multifocal splenic infarctions and hypodense area in the left liver lobe.

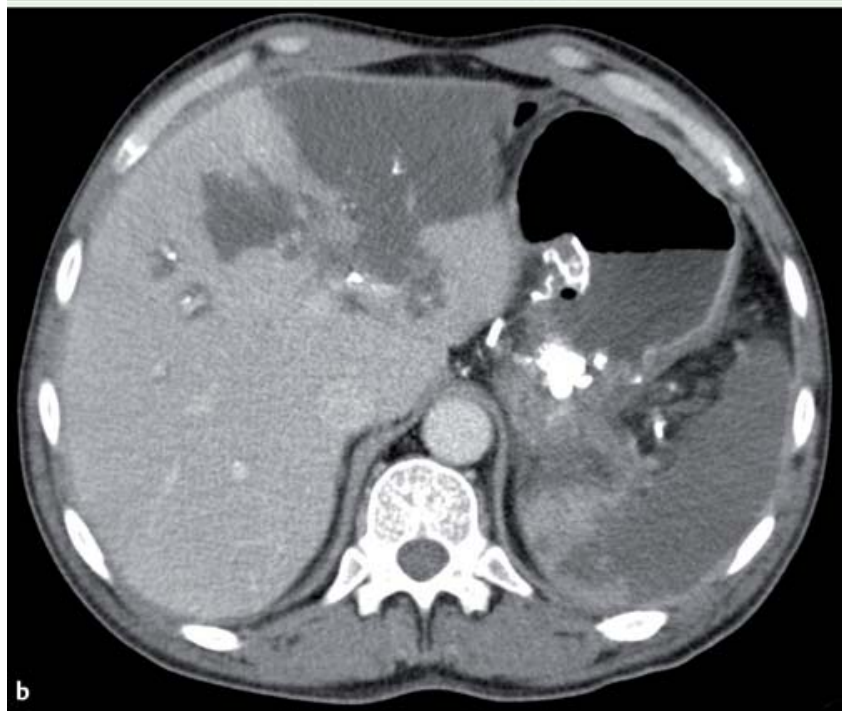


scopic treatment of bleeding peptic ulcers [3].

Endoscopy_UCTN_Code_CCL_1AZ_2AC

Competing interests: None

\section{N. Kobilica' ${ }^{1}$ V. Flis ${ }^{2}$, V. Sojar ${ }^{1}$}

1 Surgical Clinic, Department of Abdominal Surgery, University Medical Center Ljubljana, Zaloška, Ljubljana, Slovenia 2 Surgical Clinic, Department of Vascular Surgery, University Medical Center Maribor, Ljubljanska, Maribor, Slovenia

\section{References}

1 Oida T, Mimastu K, Kawasaki A et al. Splenic infarction and abscess after endoscopic injection of hypertonic saline-epinephrine solution administered for bleeding gastric ulcer. Endoscopy 2008; 40 (Suppl. 02): E239

2 Molina Infante J, Fernandez Bermejo M, Vinagre Rodriguez G. Severe gastric ischemia after combined sclerotherapy for bleeding gastric ulcer. Endoscopy 2011; 43: E191

3 Lee KJ, Kim JH, Hahm KB et al. Randomized trial of N-Butyl-2-Cyanoacrylat compared with injection of hypertonic saline-epinephrine in the endoscopic treatment of bleeding peptic ulcers. Endoscopy 2000; 32 (Suppl. 07): 505-511

\section{Bibliography}

Dol http://dx.doi.org/ 10.1055/s-0032-1308923 Endoscopy 2012; 44: E204-E205 (c) Georg Thieme Verlag KG Stuttgart · New York ISSN 0013-726X

\section{Corresponding author}

\section{Dr. N. Kobilica}

Surgical Clinic

Department of Abdominal Surgery University Medical Center Ljubljana Zaloška 7

1000 Ljubljana

Slovenia

nina_kobilica@yahoo.com 